\title{
Formação docente e relações étnico-raciais: narrativas de professoras do ensino fundamental
}

\author{
Elder Bruno Ferreira Fernandes \\ Benedito Gonçalves Eugênio \\ Mary Weinstein
}

\section{Resumo}

A discussão das relações étnico-raciais tem ganhado vários desdobramentos no cenário nacional, em especial após a promulgação da Lei 10.639/03. Este artigo apresenta os resultados de uma pesquisa sobre a formação docente e relações étnico-raciais. Para isso, foi realizada uma pesquisa qualitativa que envolveu o uso de ateliês formativos numa perspectiva intercultural e entrevistas narrativas semiestruturadas como instrumento para a produção dos dados com um grupo de cinco professoras do ensino fundamental. A análise evidenciou as dificuldades em construir e desenvolver ações pedagógicas pautadas no incentivo e valorização de encontros positivos no cotidiano de culturas plurais no ambiente escolar.

Palavras-chave: Formação docente; Interculturalidade; Relações Étnicoraciais. 


\title{
Teacher training and ethnic-racial relations: narratives of elementary school teachers
}

\author{
Elder Bruno Ferreira Fernandes \\ Benedito Gonçalves Eugênio \\ Mary Weinstein
}

\section{Abstract}

The discussion of ethnic-racial relations has got several developments in the national scenario, especially after the promulgation of the law 10.639/03. This article shows the results of a research about teachers formation and ethnic-racial relations. For this, a qualitative research was carried out involving the use of formative workshops in an inter-cultural perspective and half-structured narrative interviews as an instrument for the obtainment data with a group of five elementary school teachers. The analysis showed the difficulties in constructing and developing pedagogical actions based on encouraging and valuing positive encounters in the daily life of pluralistic cultures in the school environment.

Keywords: Formation; pluralistic cultures; Ethnic-racial relations. 


\section{Introdução}

É no ambiente escolar que há os encontros sistemáticos entre sujeitos singulares e os saberes socialmente produzidos. As dinâmicas de produção de sentido norteadora desses encontros são resultantes de complexos movimentos que se propõem a variados objetivos. Tendo a escola o objetivo da promoção da igualdade, entendida aqui pela definição de Candau (2016) como que se opõe à desigualdade e não à diferença, uma proposta possível é o caminhar pelas vias do diálogo que respeite as diversidades.

No século XX as discussões sobre a concepção social do ser ganham renovado fôlego. O fenômeno da globalização trouxe novas problematizações sobre a composição das identidades culturais do sujeito. $\mathrm{O}$ contexto relacional entre as diferentes culturas passa pela tensão advinda do dilema entre concepções universalizantes versus as particularidades culturais dos diversos povos no globo. Ao questionar a hierarquização entre as culturas, diferentes campos das ciências humanas, a exemplo da Antropologia, Sociologia e Educação contribuem para evidenciar que o caráter de hierarquia de uma cultura para com outra não se sustenta atualmente.

Ao mesmo tempo em que a discussão sobre culturas é cada vez mais pluralizada, também o é no que se refere às identidades culturais dos sujeitos. Para compreender a diversidade como fundamento do diálogo intercultural, é preciso compreender que o sujeito contemporâneo é múltiplo.

Essa visão ganha força nas palavras de Lima (2009, p. 66) ao dizer que a ideia de sujeito fixo perde lugar para "a visão de sujeito como ser descentrado, resultando nas identidades contraditórias, fragmentadas".

Na escola, espaço em que deve estar presente a ideia do sujeito como múltiplo e da não hierarquização entre os diferentes aspectos culturais, torna-se pujante a necessidade da ressignificação de estratégias pedagógicas que colaborarem para a produção de saberes não coloniais. Para que contribuição mútua entre os diferentes tipos de saber ocorra de fato, é necessário que os saberes nativos encontrem espaços alternativos e originais onde sua sabedoria possa se manifestar e onde possam se afirmar enquanto agentes virtuais de escrita com seus registros, metodologias e pensamentos diferenciados (LIMA; CARVALHO; RIBEIRO, 2018, p. 94).

Andar na contramão de padronizações e hierarquizações de saberes tendo a diferença como característica inalienável do ser é a proposta primeira de uma educação intercultural. Uma educação interculturalmente orientada passa pela incorporação da diversidade cultural presente na sociedade, pela interação entre as culturas e abertura para o diálogo (OLIVEIRA, 2017, p. 20). A abordagem intercultural está focada nas diferenças internas dos próprios 
grupos e não apenas entre os grupos, e nisso se distinguem do multiculturalismo (OLIVEIRA, 2017, p. 21).

Segundo Lima (2009, p. 68), a perspectiva intercultural envolve mais que a tolerância ao outro diferente de mim. Implica em seu relacionamento, no diálogo entre os que diferem, a construção de um projeto comum, no qual as diferenças sejam integradas como patrimônio comum.

O presente artigo apresenta os resultados de uma pesquisa-formação, realizada por meio de ateliês formativos, com professoras do ensino fundamental, com o intuito de compreender suas narrativas relacionadas ao percurso formativo e ação pedagógica acerca das relações étnico-raciais na escola. Os fundamentos metodológicos foram erigidos com autores que dialogam com as contribuições da pesquisa autobiográfica, narrativas e pesquisa-formação por intermédio de ações biográficas-formativas.

Pesquisas nessa vertente são importantes por servirem de fonte instigadora de questionamentos e reflexões que caminham no sentido de fortalecer e contribuir com ações pedagógicas voltadas para a promoção do diálogo cooperativo no ambiente escolar.

Assim sendo, pesquisas que dialogam com a formação docente e relações étnicoraciais numa perspectiva intercultural, tendo a narrativa como instrumento de análise dos dados, ajudam a compreender de que forma a temática vem sendo tratada no cotidiano escolar.

\section{Metodologia}

Um dos instrumentos utilizados na pesquisa foi a realização de ateliês formativos, em um total de sete encontros com cinco professoras do ensino fundamental. A proposta central que orientou os encontros envolveu discussões relacionadas ao processo formativo ligado às questões étnico-raciais numa perspectiva intercultural. Para a construção e análise dos dados, fez-se uso das narrativas autobiográficas e pesquisa-formação.

Entende-se aqui por ateliês formativos o proposto por Delory-Momberger (2006), que os descreve como dinâmicas propiciadoras de reflexões de um grupo em torno de experiências pessoais e profissionais como fonte produtora de conhecimento. Para Josso (2010), as narrativas relacionadas às experiências individuais trazem elementos do passado filtrados pelo presente. Não se trata de um simples retorno ao passado e sim uma mobilização de novas compreensões que se constroem por intermédio do pensar reflexivo. Os ateliês foram assim organizados: 
Tabela 01: Ateliês formativos

ATELIÊ DE FORMAČ̃̃O 01

\section{ATIVIDADE}

Entrega do Kit Pedagógico

Entrega e leitura dos documentos necessários para a realização das atividades: Termo de Consentimento Livre e Esclarecido (TCLE)/Termo de Autorização de Imagem e/ou Depoimentos

Aplicação do questionário investigativo voltado a formação profissional docente

\section{DESENVOLVIMENTO}

Entrega do classificador contendo material de uso pedagógico junto com os textos a serem utilizados em todos os encontros para que os membros do Grupo de formação possam estudar, registrar informações, conteúdos e etc.

Assinatura dos termos pelos cursistas

Coleta de Informações acerca da Formação Docente (Inicial e Continuada)

ATELIÊ DE FORMAÇÃO O2

TEMA: CULTURAS NEGADAS E SILENCIADAS NO CURRÍCULO

TEXTO UTILIZADO: SILVA, T. T. Alienígenas na Sala de Aula. In: SANTOMÉ, J. T. et al. (Orgs).

As Culturas Negadas e Silenciadas no Currículo. 3. ed. Petrópolis, RJ: Vozes, 1995. Cap. 7, p. 159

$-177$.

ATIVIDADE

\section{DESENVOLVIMENTO}

Exposição dialogada: A articulação entre 0

currículo escolar com a perspectiva Momento Discursivo 1

eurocêntrica

Exposição dialogada: As vozes negadas e silenciadas

Momento Discursivo 2

ATELIÊ DE FORMAÇÃO O3

TEMA: PLURALIDADE RACIAL: UM NOVO DESAFIO PARA A PSICOLOGIA

TEXTO UTILIZADO:

OLIVEIRA, C. M. Pluralidade Racial: Um Novo Desafio para a Psicologia. Rev. Psicologia, Ciência

e Profissão. SP, v.22, p. $34-45,2002$.

ATIVIDADE

DESENVOLVIMENTO

Exposição dialogada: Refletir sobre os elementos que constituem o racismo e a discriminação por meio de uma Momento Discursivo perspectiva psicossocial.

ATELIÊ DE FORMAÇÃO 04

TEMA: A CONSTRUÇÃO DA IDENTIDADE DA CRIANÇA NEGRA NA EDUCAÇÃO INFANTIL TEXTO UTILIZADO:

SILVA, L. M.; RIBEIRO, D. M. A Ressignificação de uma Pedagogia: Construção da Identidade da Criança Negra na Educação Infantil. Disponível em:<www.unesp.br/Home/debateacademico/artigo_revisado_layla_maryzandra-1.pdf > Acesso em: 24 abr. 2018.

ATIVIDADE

DESENVOLVIMENTO

Exposição dialogada: Possíveis consequências Momento Discursivo

da discriminação racial na construção da

identidade em crianças e adolescentes. 


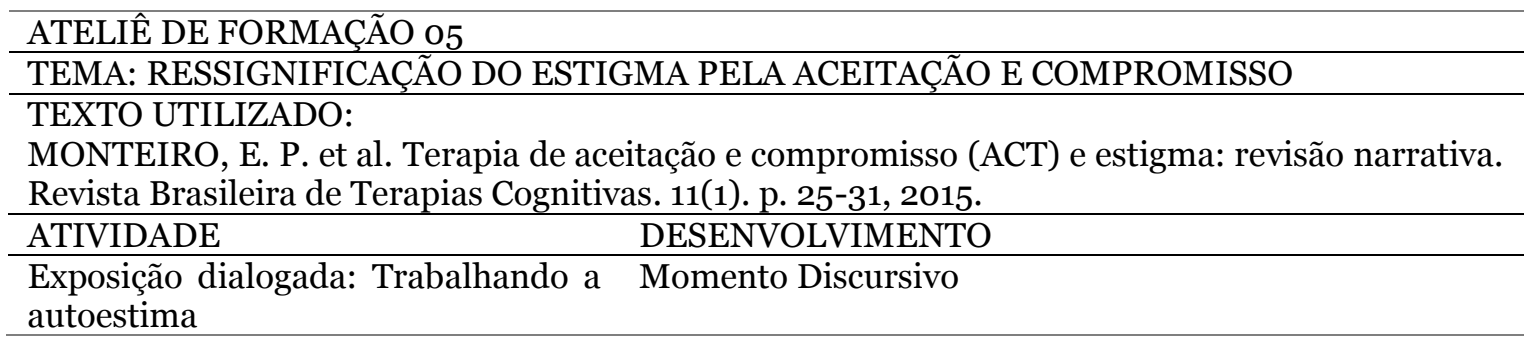

\begin{tabular}{|c|c|}
\hline \multicolumn{2}{|l|}{ ATELIÊ DE FORMAÇÃO o6 } \\
\hline TEMA: CORPO NEGRO E CABELO CRESPO & \\
\hline $\begin{array}{l}\text { TEXTO UTILIZADO: } \\
\text { GOMES, N. L. Trajetórias Escolares, Corpo Neg } \\
\text { Ressignificação Cultural? Universidade Fede } \\
\text { Set/Out/Nov/Dez, 2002. № 21. Disponível em: } \\
\text { em } 24 \text { abr. 2018. }\end{array}$ & $\begin{array}{l}\text { o e Cabelo Crespo: Reprodução de Estereótipos ou } \\
\text { al de Minas Gerais, Faculdade de Educação. } \\
\text { www.scielo.br/pdf/rbedu/n21/n21ao3.pdf > Acesso }\end{array}$ \\
\hline ATIVIDADE & DESENVOLVIMENTO \\
\hline $\begin{array}{l}\text { Exposição dialogada: O corpo com campo da } \\
\text { manifestação indenitária }\end{array}$ & Momento Discursivo \\
\hline
\end{tabular}

\begin{tabular}{c}
\hline ATELIÊ DE FORMAÇÃO 07 \\
\hline TEMA: Socializando Saberes \\
\hline Fonte: Elaborada pelos autores
\end{tabular}

Desenvolver um trabalho tendo como marco de análise dados advindos de ateliês formativos que relacionam histórias de vida e formação em um diálogo intercultural frente às questões étnico-raciais é trilhar por caminhos pavimentados pela ideia de construir positivamente ressignificações para com a ação pedagógica. O pressuposto deste tipo de pesquisa é que:

O trabalho de pesquisa a partir da narração das histórias de vida ou, melhor dizendo, de histórias centradas na formação, efetuado na perspectiva de evidenciar e questionar as heranças, a continuidade e a ruptura, os projetos de vida, os múltiplos recursos ligados às aquisições de experiência, etc., esse trabalho de reflexão a partir da narrativa da formação de si (pensando, sensibilizando-se, imaginando, emocionando-se, apreciando, amando) permite estabelecer a medida das mutações sociais e culturais nas vidas singulares e relacioná-las com a evolução dos contextos de vida profissional e social. (JOSSO, 2007, p 414).

A pesquisa-formação é aqui entendida pela definição dada por Josso (2004, p. 85) quando diz que se trata de "uma metodologia de pesquisa e de formação orientada por um projeto de conhecimento coletivo e individual, associado a um processo de formação existencialmente individualizado". 
O conceito de interculturalidade é aqui entendido conforme a definição proposta por Candau (2014, p. 4) ao dizer que ela promove uma deliberada inter-relação entre diferentes sujeitos e grupos socioculturais de uma determinada sociedade, isto é:

Concebe as culturas em contínuo processo de construção, desestabilização e reconstrução; tem presente os mecanismos de poder que permeiam as relações culturais, assume que estas não são relações idílicas, estão construídas na história, e, portanto, estão atravessadas por conflitos de poder e marcadas pelo preconceito e discriminação de determinados grupos socioculturais.

A construção e análise dos dados por meio da entrevista narrativa nesta pesquisa se valeram das proposições de Jovchelovich e Bauer (2002, p. 95):

Conceitualmente, a ideia da entrevista narrativa é motivada por uma crítica do esquema pergunta-resposta da maioria das entrevistas. No modo pergunta-resposta, o entrevistador está impondo estruturas em um sentido tríplice: a) selecionando o tema e os tópicos; b) ordenando as perguntas; c) verbalizando as perguntas com sua própria linguagem.

Para se conseguir uma versão menos imposta e por isso mais válida da perspectiva do informante, a influência do entrevistador deve ser mínima e um ambiente deve ser preparado para se conseguir esta minimização da influência do entrevistador. As regras de execução da entrevista narrativa restringem o entrevistador. A entrevista narrativa vai mais além que qualquer outro método ao evitar uma pré-estruturação da entrevista. E o empreendimento mais notável para superar o tipo de entrevista baseado em pergunta-resposta. Ela emprega um tipo específico de comunicação cotidiana, o contar e escutar história, para conseguir este objetivo.

A entrevista narrativa, por trazer as experiências e trajetórias do sujeito, procura entender a relação entre o indivíduo e a estrutura social. Foram entrevistadas 05 docentes com diferentes pertencimentos raciais e participantes de um processo de pesquisa-formação. De posse dos dados, estes foram organizados em unidades temáticas. Segundo Souza (2014, p. 4346), o mapeamento e a análise das unidades temáticas perpassam por três tempos que mantêm aproximações entre si.

(...) o Tempo I centra-se na organização e leitura das narrativas, tendo em vista a construção do perfil do grupo pesquisado, para, em seguida avançar na leitura cruzada, a fim de apreender marcas singulares, regularidades e irregularidades do conjunto das histórias de vida-formação.

No que se refere ao Tempo II - Leitura temática ou unidades de análise temática/descritiva -, cabe destacar que o mesmo vincula-se às leituras cruzadas (Tempo I), tendo em vista a construção do perfil biográfico do grupo pesquisado e a possibilidade de apreensão de regularidades, irregularidades, particularidades e subjetividades de cada história individualmente e do conjunto das narrativas do grupo, mediante a organização temática e agrupamento de unidades de análise que possibilitam a compreensãointerpretação do texto narrativo, através do seu universo de significados e significantes. Cabe destacar que o objeto central da análise temática, como ISSN 2526-2882

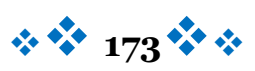


tempo II, consiste na construção, após a leitura cruzada, das unidades de análise temática, tendo em vista a análise compreensiva-interpretativa.

O Tempo III - análise interpretativa-compreensiva - vincula-se ao processo de análise, desde o seu início, visto que exige leituras e releituras individuais e em seu conjunto do corpus das narrativas, recorrendo aos agrupamentos das unidades de análise temática e/ou ao conjunto das narrativas e das fontes utilizadas.

Esses tempos foram considerados na elaboração das unidades temáticas. Considerando os tempos I e III, duas são as unidades temáticas apresentadas neste artigo: Formação docente e relações étnico-raciais; Diversidade religiosa e as relações étnico-raciais na escola. A pesquisa foi submetida e aprovada pelo Comitê de Ética em Pesquisa (CEP/UESB) sob o número CAAE 89815118.0.0000.0055.

\section{Resultados e discussões}

Conforme já mencionado, os dados construídos nos ateliês foram organizados em unidades temáticas. Duas dessas unidades são discutidas a seguir.

\section{Formação docente e relações étnico-raciais}

No cotidiano escolar, o exercício do magistério torna o docente um agente multiplicador de ações afirmativas. Por isso a importância de a ação pedagógica está atrelada a uma prática crítica no desenvolvimento do currículo com os alunos, principalmente devido ao fato de que:

A sociedade ocidental moderna - capitalista, heterogestionária, patriarcal, viciada em hierarquias - parece ser viciada na segregação do diferente. Um dos alicerces morais dessa sociedade parece ser que confirmamos nossa lealdade ao grupo ao afirmar a deslealdade de outros. (OLIVEIRA, 2002, p. 35).

Reside nesse fato à importância da formação continuada dos docentes, tendo em vista que:

A ação educativa pretende, portanto, além de desenvolver capacidades para a tomada de decisões, propiciar aos alunos e às alunas e ao próprio professorado uma reconstrução reflexiva e crítica da realidade, tomando como ponto de partida as teorias, conceitos, procedimentos e costumes que existem nessa comunidade e aos quais se devem facilitar o acesso. Nesse trabalho de formação de pessoas críticas, ativas e solidárias, e de ajuda na reconstrução da realidade, é imprescindível prestar uma atenção prioritária aos conteúdos, assim como, naturalmente, às estratégias de ensino e aprendizagem e avaliação para levar a cabo tal missão. (SILVA, 1995, p. 160). 
A construção do currículo escolar não é neutra e tampouco inocente, conforme já apontaram as teorias críticas desde a década de 1970. Quando a formulação curricular direciona a compreensão do estudante para uma categorização e hierarquização de saberes e culturas, ela fomenta uma percepção deturpada do mundo. Os saberes resultantes desse processo, o da hierarquização das diferenças, categorizam pejorativamente, o que difere por atribuir-lhes sentidos de descrédito e inferioridade.

\begin{abstract}
A narrativa do mito da diferença, que é categoria necessária à justificativa do preconceito, é a redenção e a salvação do passado característica da escatologia que é a mitologia do contemporâneo, oferecendo o ideal heroico de ser humano imposto na sociedade brasileira atual (branco, rico, do sexo masculino, heterossexual e cristão). (...) isso constitui o fetichismo contemporâneo, onde é possível dizer que realidade e ilusão se misturam. Somente o sujeito esvaziado de si mesmo, o sujeito que mistura realidade e ilusão, esse sujeito imagético do capitalismo contemporâneo é capaz de aceitar o preconceito da forma como ele se impõe. (OLIVEIRA, 2002, p. 36).
\end{abstract}

Os "conhecimentos estereotipados internalizados afetam os indivíduos, uma vez que o preconceito e a desvalorização são antecipados, processo denominado consciência do estereótipo" (MONTEIRO et. al, 2015, p. 26). Por meio de uma práxis pedagógica implicada na construção de pensamentos emancipatórios, a sala de aula passa a ser um ambiente que potencializada questionamentos potentes para a produção do cidadão ético e crítico-reflexivo.

As situações cotidianas do trato com o outro apontam para a necessidade cada vez mais premente de investimento na formação continuada dos docentes para o trabalho com a educação das relações étnico-raciais e o combate ao racismo, pois este opera de modo sutil, adoece e interfere diretamente na construção identitária e autoestima dos estudantes negros e negras.

O combate ao racismo no cotidiano escolar não é uma meta obtida por práticas pedagógicas restritas a datas comemorativas, precisa fazer parte das ações cotidianas da escola e figurar em seu projeto político-pedagógico.

\begin{abstract}
Algo que é preciso ter em conta é que uma política educacional que queira recuperar essas culturas negadas não pode ficar reduzida a uma série de lições ou unidades didáticas isoladas destinadas a seu estudo. Não podemos cair no equívoco de dedicar um dia do ano à lutar contra os preconceitos racistas ou a refletir sobre as formas adotadas pela opressão das mulheres e da infância. (SILVA, 1995, p. 172).
\end{abstract}

Não são poucos os desafios em transformar as salas de aula em lugares que privilegiam ações reflexivas em detrimento de práticas de improvisos. Posicionar-se contra 
ações pedagógicas atreladas ao ritmo ditado de ideologias segregadoras requer mais do que coragem.

\section{Formação inicial, trabalho docente e relações étnico-raciais}

Mesmo decorrido 16 anos da aprovação da Lei 10.639/o3, Estados e Municípios tem encontrado dificuldades em promover a implantação da educação das relações étnico-raciais no currículo, conforme apontaram as pesquisas de Gomes (2013), Baia Coelho (2014), Eugenio; Santana (2018), Eugenio; Santos; Souza (2017), Müller; Coelho; Ferreira (2015), dentre outros.

Essas dificuldades se estendem também para as licenciaturas, tendo em vista que muitos currículos não contemplam esta temática na formação dos professores, segundo constataram Passos (2014), Nogueira (2016), Cardoso; Castro (2015).

As narrativas das professoras participantes da pesquisa revelam fragilidades advindas do processo formativo. Para além da formação inicial, a formação continuada é aqui percebida como um processo pouco eficiente, seja pela sua pouca oferta ou pela superficialidade que lidam com a temática étnico-racial.

Prof. Diana - Fiz umas pós-graduações fracas que nem vou colocar aqui.

Prof. Laila - Oh, eu também. Esqueci.

Prof. Ártemis - É aquela que não serviu de nada ...

Prof. Laila - Se eu tenho conhecimento dessa lei? Eu não tenho não. É tanta lei.

Há a ausência, por parte do município, da promoção de práticas voltadas à implementação de formação continuada capaz de abarcar uma quantidade significativa de professores, conforme identificamos nas narrativas a seguir:

Prof. Laila - Mesmo que em sociologia a gente conversou a mistura da cor. É que todo mundo na família tem um branco, um negro. Mesmo que trabalhamos conteúdos nesse sentido, mas de falar de étnico-raciais, não. Já teve alguém falando sobre isso na cidade, mas só poderia um ou dois professores. Aí só veio uma vaga para a escola e eu não fui. Foi por sorte.

Prof. Laila - Eu não participei. Essas coisas quando vem é para poucos. Foi sorteio. E a secretaria não ia liberar esse tanto de professores.

Prof. Ártemis - Eu não tomei [o curso oferecido pelo município]. Eu estudei agora para fazer o PPP.

A pouca oferta de encontros voltados para uma formação continuada fragiliza a construção de uma pedagogia voltada à desconstrução do racismo existente nas escolas. Tal posicionamento ganha renovado fôlego quando nos atentamos para a existência de uma 
ausência de uma política nacional bem articulada capaz de garantir uma melhor qualificação na formação inicial nos cursos de licenciatura.

As pesquisas apontam o quanto à ausência de uma política nacional dessa natureza contribui para o esgarçamento das formações de professores em diferentes modalidades e níveis de ensino. Não se conta nem com uma consolidação de normas existentes e vigentes, as quais foram sendo elaboradas em vários tempos e sobre variadas pressões, e que se encontram dispersas em leis, resoluções, portarias, pareceres, documentos orientadores etc. Conta-se, em nível nacional, não com uma política geral relativa à formação de professores, mas com uma política parcial orientada para a formação em serviço de quadros não suficientemente titulados nas redes educacionais. (GATTI, 2014, p. 34).

A prática pedagógica interculturalmente orientada deve adquirir o status de prática permanente no ambiente escolar, principalmente pelo fato de que o racismo está presente na estrutura social brasileira e atinge diretamente os estudantes. O perigo em lidar equivocadamente com essa questão é o de fortalecer a hierarquização de particularidades culturais.

Vale repetir: há uma luta para manter o monopólio sobre o que é universal, posto que tal monopólio constitui-se como um dos meios fundamentais para a reprodução simbólica das elites globais. Uma vez que se define o que é universal, quanto mais um grupo ou uma pessoa se enquadram na definição, mais globais eles se tornam (LIMA; CARVALHO; RIBEIRO, 2018, p. 52)

No cotidiano da sala de aula as docentes lidam diretamente com situações envolvendo a prática do racismo e da discriminação racial. Contudo, atitude ainda presente é abordar a temática sem que haja planejamento para o trabalho com a educação das relações étnicoraciais, conforme narrou a professora. Laila:

Prof. Laila - eu não penso nisso não (Referindo-se a inclusão no planejamento das aulas sobre temáticas ligadas às questões étnico-raciais). Às vezes você está trabalhando um conteúdo e tem que relacionar com isso aí, com alguma coisa nesse sentido. Principalmente pela manhã que trabalho com crianças menores e eles são muito de falar: fulano é preto. Fulano é que nem não sei o quê. Fulano faz isso. Aí você tem que levar a base da história para eles compreenderem que a pele não é nada. Ela não influência no pensar e raciocinar e no fazer as coisas. Mas se eu dizer para você que eu planejo minha aula em cima disso aí eu estarei mentindo. Mas isso ocorre muito dentro da minha aula, muitas e muitas vezes.

Eu falei aqui que na minha formação não teve, mas eu estudei um livro que vem mostrar como foi a construção do Brasil e que muitas coisas devem aos negros. Nós tivemos seminários falando sobre racismo, sobre o negro no Brasil, essas coisas. Eu detesto preconceito e discriminação. Vou mostrando para eles como foi a história para diminuir esses preconceitos.

Eu tenho um aluno que além de preto e cambotinha, cabeça torta, é complicado. Ainda bem que nenhum deles trata ele com discriminação. 
O planejamento das ações pedagógicas em sala de aula demanda do professor a construção de estratégias que alinhem o conhecimento socialmente produzido com objetivos estabelecidos no currículo. A narrativa acima expressa as dificuldades que os docentes têm para a abordagem das relações étnico-raciais na sala de aula. Ainda vigora o currículo turístico (SANTOMÉ, 1995), baseado em unidades didáticas isoladas. Além disso, expressa também o que Cavalleiro (2000, p. 35) apontou:

é flagrante a ausência de um questionamento crítico por parte das profissionais da escola sobre a presença de crianças negras no cotidiano escolar. Esse fato, além de confirmar o despreparo das educadoras para relacionarem com os alunos negros evidencia, também seu desinteresse em incluí-los positivamente na vida escolar. Interagem com eles diariamente, mas não se preocupam em conhecer suas especificidades e necessidades.

Alguns desafios vigoram nesse momento específico. Percebendo uma demanda específica em sala de aula relacionada às questões étnico-raciais, o profissional da educação deve, ainda que minimamente, caminhar na contramão da validação de conceitos estereotipados. Ações pedagógicas que se propõem interculturais não devem ater-se a um sistema de regulação que legitime subordinações hierárquicas na sala de aula.

É inviável pensar uma sociedade como um conjunto monocultural. Essa lógica também se aplica as salas de aula. Ainda que implicitamente, a perspectiva intercultural precisa estar articulada com as ações pedagógicas.

El sistema educativo es, sinduda, una de las instituciones sociales más importantes para construir la interculturalidad, ya que es la base de la formación humana e instrumento no sólo de mantenimiento de una sociedad sino de su crecimiento, transformación y liberación, y del reconocimiento de todas sus potencialidades civilizatorio-humanas (WALSH, 2009, p. 183).

Lidar com as práticas racistas e/ou de preconceito racial permeou o cotidiano de algumas das docentes participantes da pesquisa. $\mathrm{O}$ acesso às discussões na formação inicial mostrou-se fundamental para a desconstrução do racismo.

Prof. Diana - eu lembro que quando criança, por eu ser a mais moreninha da casa, me chamavam de a negra do rancho... assim sabe, aquelas brincadeiras bestas. Eu me lembro que falavam que iria casar com o negro do Rancho. Eu lembro que a gente ia para os torneios e eventos que tinham lá e os parentes falavam que a gente era a negra do Rancho. Hoje eu vejo que irmãos meus relacionaram com meninas de lá e não foram aceitos. Não por parte dos meus pais. O pai da minha avó era um homem negro e ela não aceita. Ela fala que ela não aceita que alguém dela case com um negro. Por conta disso eu cresci com essa ideia de que o negro era inferior. Eu fui desconstruir isso já na faculdade por intermédio de leituras. Eu entrei em alguns grupos de estudo e a gente acaba se aproximando dessas discussões. 
Essas questões foram tão fortes na minha vida que eu era super racista. Minha irmã namorava um rapaz negro e eu falava que eu nunca namoraria um rapaz negro. Só que à medida que eu comecei a estudar, eu me disponibilizei a dialogar e não me fechei para o mundo. A faculdade abriu muito a minha cabeça a ter pensamentos melhores. Hoje eu busco desconstruir isso principalmente pela forma que eu pensava.

Com o passar do tempo eu comecei a namorar um rapaz negro e no dia em que eu apresentei ele para minha irmã eu senti vergonha dele. Eu avisei para ela antes que ele era feio. Eu fiz aquele terror sabe...

Ainda bem que eu desconstruí isso e levar essa mensagem naquilo que eu posso, na minha prática pedagógica.

Quanto à formação acadêmica, a questão vai muito além da mera inclusão da diversidade cultural nos programas curriculares. Dialogar sobre a cultura ou tradições africanas não representa necessariamente a ressignificação de crenças estereotipadas. Quando abordado de uma maneira não reflexiva, a ação educacional pode corroborar com o fortalecimento de ideias preconceituosas enquanto acredita ingenuamente que caminha na direção da desconstrução do racismo, pois pode incorrer na prática do multiculturalismo liberal de direita.

\begin{abstract}
Los esfuerzos actuales por evaluar y clasificar a las universidades latinoamericanas bajo criterios "universales", y estabelecer criterios similares para los colegios y los docentes, e sun buen ejemplo. Sonestos "estándares" de calidadlos que también impulsan y orientan la nueva filosofía y política de la inclusión; "incluir" a los grupos históricamente marginalizados podría ser estrategia clave de un mundo globalizado, donde nada ni nadie puedan quedar fuera de los designios del mercado. Por lo tanto, el reconocimiento de los pueblos indígenas y afrodescendientes, y la incorporación dentro del currículo de "algo" de sus tradiciones, folclor y saber, no reflejan necesariamente una nueva conciencia social. Por el contrario, esto puede ser comprendido como el cumplimiento de las nuevas reglas del multiculturalismo de corte neoliberal. Mientras la nueva bandera multicultural proclama la inclusión, su paradigma perpetúa y legitima formas de diferenciación excluyente e inventa nuevas formas novedosas. La vieja dicotomía entre ciencia -o conocimiento- y saber se mantiene vigente; los indígenas y negros quedan marcados y representados por su diferencia no moderna y por su particularidad cultural (subalternizada, esencializada y etnizada) frente a la mismidad de los sectores blanco-mestizos (WALSH, 2009, p. 192).
\end{abstract}

Os universitários tendem a ganhar muito quando as universidades passam a se organizar curricularmente para uma virada epistêmica, particularmente nos cursos de formação de professores, em que as relações étnico-raciais sejam abordadas de forma interdisciplinar pelos docentes.

\title{
Diversidade religiosa e as relações étnico-raciais na escola
}

A diversidade religiosa, certamente uma das temáticas em que há maior resistência pelos docentes para o trabalho com a Lei 10.639/03, também precisa se fazer presente na 
formação dos professores, conforme apontou Santos (2018), tendo em vista que ainda prevalece a referência tão somente à matriz judaico-cristã.

Prof. Isis - Bem, eu dou aula de religião e eu levo a bíblia para a sala assim como eu levo o livro de ciências. E eu costumo dar a aula de acordo com a bíblia. Eu relato as histórias da bíblia de gêneses a apocalipse. Porém, eu também falo que existe outras religiões. Pergunto na sala também se você (aluno) costuma ir na igreja, você tem uma religião definida... eu tenho alunos que são da umbanda que me relataram que sofrem discriminação. Teve uma que veio me perguntar se eu acreditava em Maria. Eu falo segundo o que está na bíblia. Eu procuro ater minha opinião para não falar que eu estou direcionando a minha que sou evangélica. Eu não direciono a minha religião. Eu falo "segundo a bíblia" ...a sua bíblia fala e a minha fala isso. Que lá fala que nós não devemos cultuar imagens. A bíblia fala isso. Agora, se na sua permite a fazer isso você pode fazer. Eu como professora, eu falo do livro que eu sigo que é a bíblia. Êxodo vinte fala que nós não podemos cultuar imagens, mas existem pessoas que fazem. Quem sou eu de ir contra. A sua posição é essa eu respeito. Agora eu não faço. Você tem a sua religião, mas tem que ter cuidado e respeito para não machucar ninguém. Mas tem o lado do esclarecimento. Às vezes você vai por causa da sua família. A aula de religião é uma das aulas mais difíceis de se dar. Você tem que ter conhecimento mesmo.

Ao discutir a inclusão efetiva das temáticas étnico-raciais na escola, as narrativas das professoras participantes do estudo demonstram as dificuldades da comunidade escolar com o acolhimento para com temáticas ligado às religiões de matriz africana. Essa problemática que envolve o que é sagrado para uma vertente não judaico-cristã, encontra uma resistência manifesta no cotidiano escolar.

Há equivocadamente uma representatividade de características negativas quando o assunto é religião de matriz africana. As associações estereotipadas em uma perspectiva hierarquizante que coloca a religião de matriz africana sobre o crivo da religião judaico cristã impossibilitam a problematização dessa temática no cotidiano das escolas.

O fato é que mesmo sendo a principal agência do saber sistematizado, responsável pela sua produção e reprodução, e também espaço privilegiado para o desenvolvimento de juízos ponderados, através da cognição, a escola ainda não é um locus ao qual se possa atribuir pleno êxito na tarefa de construção de sujeitos autônomos, críticos e comprometidos com as mudanças e exigências do seu tempo (SANTOS, 2017, p. 759).

As formas de ver e pensar o mundo ligada à matriz civilizatória eurocêntrica ainda estão intimamente ligadas à gênese cultural brasileira a ponto de desfigurar qualquer outra referência que não a dela. Sem uma postura reflexiva coerente com os princípios da educação intercultural, qualquer tentativa que busque percorrer outros caminhos será negada no espaço escolar. 
A tradição judaico-cristã assume uma posição quase que imune a visões contrárias à sua e isso permeia a ação pedagógica, reduzindo o outro a uma perspectiva que obedece a uma lógica unifocal. Por esses caminhos, o ambiente plural escolar deixa de ser um espaço de potencialidades para a construção de saberes diversos para se tornar um ambiente hostil para alguns sujeitos, conforme apontam as narrativas das docentes transcritas a seguir.

Prof. Diana- Não é especificamente a aula, podemos trabalhar sobre as religiões sem defender uma específica. Mas pensando a escola como um todo, quem tem voz? Quando que uma religião afro, por exemplo, teve espaço dentro da escola? Quando que uma pessoa de uma religião afro foi convidada para falar sobre sua religião dentro da escola? A base política da escola entra em questão. Falar em sala de aula até que se consegue, mas como um todo, a voz dessas pessoas não prevalece. Não é nem prevalecer, porque o prevalecer vai entrar em uma relação de poder porque ela vai ficar em destaque e outras vão ficar excluídas. E não é isso. Mas é o espação que essas pessoas precisam e que a escola não tem.

Prof. Isis - E outra observação aí também é que tem poucos livros que falam, poucos documentários. E quando eu coloco a bíblia, a bíblia já tem há milhões de anos. Então, ela já tá ali. Então é mais cômodo, é mais aceitável, já tá ali. Então, para eu colocar isso, outra religião aqui dentro é mais difícil...

Você tem que ter um preparo até porque o pai jamais vai aceitar, e não vai mesmo. Não é que o filho vai seguir. Ele vai seguir o que acha que deve, mas até para ser mostrado mesmo eles são contra, não quer nem que veja.

Professora Laila - Um dos primeiros comentários seria que isso é do candomblé. Em uma sala de aula minha eu já ouvi isso.

Professora Diana - Se bem que alguns pais poderiam se sentir comtemplados também, por se sentirem representados. Ou talvez existisse um espanto. Não ficariam satisfeitos. Mas essa reação é fruto de uma situação que nunca é mostrado na escola. Não é trabalhado. Ela é escondida. E se de repente mostrar vai ser aquela surpresa. Entre aspas.

Professora Diana - Se fala de alguma religião dentro da cristandade, não há problema. Mas se a fala é sobre a religião africana, as pessoas torcem o nariz.

Ainda que a Lei 10.639/o3 tenha estabelecido marcos regulatórios em benefício do aprofundamento dos encontros de diferentes conteúdos culturais no convívio do espaço escolar, tudo leva a crer que as vivências que ainda vigoram são típicas da matriz colonial do conhecimento. De acordo com Santos (2017, p. 759):

O apego exacerbado à crença de que a nossa matriz civilizatória é grecoromana e judaico-cristã, ao lado dos dispositivos escolares que reforçam tal crença, através dos conteúdos curriculares e rituais da escola, funcionam como obstáculos epistemológicos para uma mudança nas concepções e práticas dos docentes. Nos interstícios dessa crença encontram-se clivagens dos efeitos de sentido dos discursos já produzidos sobre as heranças africanas no Brasil. Para os que defendem a matriz greco-romana, a cultura afrobrasileira ainda é vista como expressão de incivilidade, primitivismo, atraso cultural, volúpia dionisíaca. Para os que defendem a matriz judaico-cristã, as religiões de matrizes africanas representam manifestação do culto ao demônio, atraso de vida, rituais de magia negra para produzir malefícios às pessoas, charlatanismo e completa ausência da luminosidade apolínea. Em 
razão disso, as matrizes africanas são consideradas como tradições que devem ser objeto de atenção missionária, através da evangelização.

As narrativas das professoras integrantes da pesquisa demonstram que é apropriado dizer que pautas ligadas a religiosidades de matriz africana causam uma mobilização geral na comunidade escolar. As matrizes da religiosidade judaico-cristã estão fortemente presentes nas ações pedagógicas. Propor um olhar sério, contextualizado e liberto de estereótipos quanto ao trato de religiões de outras denominações ainda se mostra como grande desafio. Compreender que diferentes denominações religiosas compõem a história da sociedade brasileira é um passo acertado para o desenvolvimento de práticas com consequências positivas no contexto educacional.

\section{Considerações finais}

Este artigo apresentou os resultados de uma pesquisa-formação acerca das relações étnico-raciais em uma perspectiva intercultural com docentes do ensino fundamental. As narrativas resultantes no processo evidenciam as problematizações e dificuldades das docentes no trato da educação das relações étnico-raciais no currículo.

As narrativas indicam os desafios enfrentados pelas professoras em construir e aplicar ações pedagógicas potentes no sentido de promover o intercâmbio positivo quanto à diversidade racial existente na escola.

Embora levem em consideração as perspectivas das relações étnico-raciais em suas ações pedagógicas, todas sentem o peso de uma formação não substancial para lidar com a temática. As dificuldades relacionadas a pouca oferta de formação continuada voltada para esse viés também ficam evidente.

O contexto das narrativas apresentadas fornece elementos que possibilitam compreender os desafios vivenciados para a criação e aplicação de ações pedagógicas que valorizem e incentivem os encontros positivos entre pessoas de diferentes pertencimentos étnicos.

Os dados construídos apontam para a necessidade de os currículos dos cursos de licenciatura tratarem a educação das relações étnico-raciais, assim como para a importância da formação continuada no espaço da escola acerca da temática, a fim de que a colonialidade do poder e do saber seja repensada por meio da adoção de práticas inclusivas de trabalho com a temática das relações étnico-raciais.

\section{Referências}

CANDAU, V. M (Org.). Interculturalizar, descolonizar, democratizar: Uma educação “outra” ?. Rio de Janeiro: Letras, 2016. 
CANDAU, V. M. Construindo Práticas Escolares Interculturais e Formação Docente. Didática e Prática de Ensino: diálogos sobre a Escola, a Formação de Professores e a Sociedade. EdUECE - Livro 4 0055. XVII ENDIPE, Fortaleza, 2014.

CARDOSO, I. A.; CASTRO, R. M. A ausência/presença das relações étnico-raciais nos currículos dos cursos de pedagogia: o caso da Unesp/Marília. Revista Práxis Educacional (online), v. 11, n. 8, p. 91-115, 2015.

CAVALLEIRO, E. Do silêncio do lar ao silêncio escolar. Educação e Poder -racismo, preconceito e discriminação na Educação Infantil. São Paulo: Summus, 2000.

DELORY-MOMBERGER, C. Formação e socialização: os ateliês biográficos de projeto. Revista Educação e Pesquisa, v. 32, n. 2, p. 359-371, maio/ago. 2006.

EUGENIO, B.; SANTANA, F. Relações étnico-raciais e o trabalho com a Lei 10.639/o3: análise de uma experiência com formação docente. Revista Ensino e Pesquisa, v. 16, n.1, p. 58-73, 2018.

EUGENIO, B.; SANTOS, J. J. R.; SOUZA, J. B.. Políticas para a implementação da Lei 10639/o3 em um município brasileiro: o discurso oficial e o discurso pedagógico. Revista Educação Temática Digital: ETD, Campinas, v. 19, n. 1, p. 283-304, jan./mar. 2017.

GATTI, B. A. Formação Inicial de Professores para a Educação Básica: Pesquisas e Políticas Educacionais. Revista Estudo em Avaliação Educacional, São Paulo, v. 25, n. 57, p. 24-54, jan./abr. 2014.

JOSSO, M. C. A transformação de si a partir da narração de histórias de vida. Revista de Educação, Porto Alegre, v. 3, n. 63, p. 413-438, set./dez. 2007.

JOSSO, M. C. Caminhar para si. Porto Alegre: Edipucrs, 2010.

JOSSO, M. C. Experiência de Vida e Formação. São Paulo: Cortez, 2004.

JOVCHELOVICH S, BAUER M. W. Entrevista Narrativa. In: Bauer M. W, Gaskell G. Pesquisa qualitativa com texto, imagem e som: um manual prático. Petrópolis: Vozes, 2002, p. 90-113.

LIMA, A. C. S.; CARVALHO, L. F. S.; RIBEIRO. G. L.;(Org.) Interculturalidade(s): entre ideias, retóricas e práticas em cinco países da América Latina. Rio de Janeiro. Associação Brasileira de Antropologia, 2018.

LIMA, E. F. Apontamentos sobre ensino e formação de professores intermulticulturais. Revista Série-Estudos, Campo Grande, n. 27, p. 65-81, jan./jun. 2009.

MONTEIRO, E. P. et al. Terapia de aceitação e compromisso (ACT) e estigma: revisão narrativa. Revista Brasileira de Terapias Cognitivas, Rio de janeiro, v. 11, n. 1, p. 25-31, jun. 2015.

$$
\text { ISSN 2526-2882 }
$$


MÜLLER, T. M.; COELHO, W. N. B.; FERREIRA, P. A. B. (Orgs.). Relações Étnico-raciais, formação de professores e currículo. São Paulo: Livraria da Física, 2015.

NOGUEIRA, R.R. A pesquisa na formação docente e a temática étnico-racial: uma análise dos TCC do curso de Pedagogia da FACIP/UFU. Dissertação (Mestrado em Educação). Faculdade de Educação, Universidade Federal de Uberlândia, Uberlândia, 2016.

OLIVEIRA, C. M. Pluralidade Racial: Um Novo Desafio para a Psicologia. Revista Psicologia, Ciência e Profissão. Brasília, v. 22, n. 4, p. 34-45, 2002.

OLIVEIRA, N. Do multiculturalismo ao interculturalismo. Um novo modo de incorporação da diversidade cultural? Revista Ambivalências, v. 5, n. 9, p. 10-35, jan./jun. 2017.

PASSOS, J. C. As relações étnico-raciais nas licenciaturas: o que dizem os currículos anunciados? Revista Poiésis, Tubarão, v. 8, n. 13, p. 172-188, jan./jun. 2014.

SANTOMÉ, J. T.(Orgs). As culturas negadas e silenciadas no currículo. In:SILVA, T. T. Alienígenas na Sala de Aula. 3. ed. Petrópolis, RJ: Vozes, 1995.

SANTOS, D. L. J. Identidades religiosas: subjetividades em conflito na formação de professores. Tese (Doutorado em Educação). Departamento de Educação, Universidade do Estado da Bahia, Salvador, 2018.

SANTOS, E. P. A educação das relações étnico-raciais, as religiões de matrizes africanas e a dupla pertença no episódio "o compadre de Ogum" na literatura de Jorge Amado. RevistaCurrículo sem Fronteiras, v. 17, n. 3, p. 756-768, set./dez. 2017.

WALSH C. Interculturalidad, estado, sociedade: luchas (de)coloniales de nuestra época. Quito: Universidad Andina Simón Bolívar / EdicionesAbya-Yala, 2009.

\section{Biografia Resumida}

Elder Bruno Ferreira Fernandes- Licenciado em História (UNEB) e Bacharel em Psicologia (Centro Universitário de Guanambi). Mestre em Ensino (UESB). Professor de História da Secretaria de Educação do Estado da Bahia. É membro do Grupo de Pesquisa Currículo, gênero e relações étnico-raciais.

Link do Lattes:http://lattes.cnpq.br/3610644515651412

e-mail: eldergbi@hotmail.com

Benedito Eugenio- Doutor em Educação (UNICAMP). Professor da Universidade Estadual do Sudoeste da Bahia e do Programa de 
Pós-graduação em Ensino (PPGEn/UESB). Líder do Grupo de Pesquisa Currículo, gênero e relações étnico-raciais.

Link do Lattes: http://lattes.cnpq.br/1274035318009124

e-mail: dodoeugenio@gmail.com

Mary Weinstein- Doutora em Cultura e Sociedade (UFBA). Professora da Universidade Estadual do Sudoeste da Bahia e do Programa de Pós-graduação em Ensino (PPGEn/UESB).

Link do Lattes:http://lattes.cnpq.br/1189328523014513

e-mail: maryweinstein@gmail.com 